\title{
Desilusión y esperanzas durante la Gran Guerra: poetas y cronistas americanos
}

\section{Hopes and dissapoinments during the Great War: American Poets and Cronicles}

\section{Decepção e esperança durante a Grande Guerra: poetas e escritores latino-americanos}

\author{
Mario Oliva-Medina \\ Instituto de Estudios Latinoamericanos \\ Recibido: 21/2/2015 -Aceptado: 30/7/2015 \\ http://dx.doi.org/10.15359/tdna.31-58.1
}

\section{Resumen}

La Gran Guerra ha generado, desde 2014, una eclosión de materiales académicos de análisis sobre este suceso histórico y político. En los acercamientos historiográficos contemporáneos se tiene a la cultura, entendida desde la perspectiva historiográfica del "giro cultural", como el elemento central de análisis: se pasa de una historia social a una historia cultural de la Gran Guerra. El papel jugado por los cronistas y poetas latinoamericanos en la Primera Guerra Mundial brinda una mirada desde la experiencia personal de ellos sobre el gran conflicto, trasladándonos de la Historia a esa otra historia cotidiana, la de los héroes anónimos, la de los mutilados y desplazados. Este artículo analiza la participación de cuatro latinoamericanos en el primer gran conflicto que irradió y afectó a toda la humanidad. Ellos son: el costarricense José Basileo Acuña (1897-1992), los nicaragüenses, Salomón de la Selva (1893-1959) y Rubén Darío (18671916); y, el guatemalteco Enrique Gómez Carrillo (1873-1927).

Palabras clave: Primera Guerra Mundial, José Basileo Acuña, Rubén Darío, Salomón de la Selva, Enrique Gómez Carrillo, pensamiento latinoamericano, historiografía, historia cultural

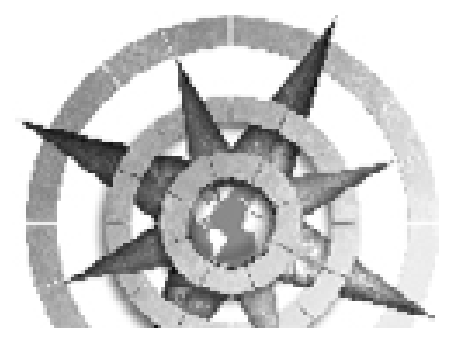

Abstract

The year 2014 witnessed a huge outcome of scholarly materials analyzing the political and 
historical milestone the World War I set. Contemporary historiographical approaches put culture into the perspective of the cultural turn, that is to say, a passage from the social history towards a cultural history in this case regarding the Big War. This article analyzes the World War I from the point of view of four Latin Americans chroniclers, Costa Rican, José Basileo Acuña (1897-1992), Nicaraguan, Salomón de la Selva (1893-1959) and the poet Rubén Darío (1867-1916), and the Guatemalan journalist, Enrique Gómez-Carrillo (1873-1927). They eye-witnessed and experienced the confrontation at first hand. Therefore, besides giving us their personal glance of the conflict, their texts also bring us closer to the day-to-day wartime history letting us know the story of the anonymous heroes, of mutilated people and the displaced victims of that first war conflict that affected all mankind.

Keywords: World War I, José Basileo Acuña, Rubén Darío, Salomón de la Selva, Enrique Gómez-Carrillo, Latin American Thinking, Cultural History

\section{Resumo}

O ano 2014 nos dá um grande resultado de materiais acadêmicos de abordagem historiográfica da Primeira Guerra Mundial. Na Historia Contemporânea fica uma abordagem baseada um novo instrumento teórico da giro cultural ou seja, o passagem da história social à história cultural da Guerra Grande.
Este artigo analisa a Primeira Guerra Mundial do ponto de vista dos cronistas Latino-Americanos; José Basileo Acuña (1897-1992) da Costa Rica, Salomón de la Selva (1893-1959) e o poeta Rubén Darío (1867-1916) da Nicarágua e Enrique Gómez-Carrillo (18731927) da Guatemala. Eles viveram e testemunharam o conflito e seus textos permitem-nos ter um olhar pessoal do Guerra. Este artigo da-nos uma abordagem da vida cotidiana em tempos de guerra e mostra-nos a história dos heróis anônimos, e de pessoas mutiladas e deslocadas através da visão destes escritores e poeta que participaram de um conflito que afetou toda a humanidade.

Palavras chave: Primeira Guerra Mundial, José Basileo-Acuña, Rubén Darío, Salomón de la Selva, Enrique Gómez-Carrillo, pensamento latinoamericano, história cultural

\section{Preludio historiográfico}

El año 2014 y lo que llevamos del presente, asistimos a una enorme actividad académica en torno a La Primera Guerra Mundial la cual se manifiesta: en una eclosión de materiales en imágenes, en sonoros, y desde luego libros, artículos y ensayos en formatos físicos y virtuales al son de las nuevas plataformas tecnológicas, al punto de ser casi imposible revisar toda la información disponible. Lo anterior, está marcado por renovados planteamientos historiográficos,

16 Desilusión y esperanzas durante la Gran Guerra: poetas y cronistas americanos

Mario Oliva-Medina 
literarios, sociales y culturales, se observa una preocupación que desplaza la atención de la parte estrictamente militar y sus consecuencias letales sobre la vida de millones de personas, la narración de las batallas, el tipo de armamento usado, en fin. Ahora la preocupación se concentra en la vida cotidiana, en la participación de los héroes anónimos, en la narrativa de múltiples historias que van construyendo una historia más humana de esta gran catástrofe de la civilización europea con su efecto irradiante sobre buena parte del planeta. En suma nos parece que los nuevos estudios abordan la belleza, la grandeza y el dolor de la guerra de modo simultáneo. No debemos olvidar que para los propios protagonistas como lo dijese Ernst Junger (2014) en uno de los libros más estremecedores de aquella contienda, Tempestades de acero: "La guerra nos parecía un lance viril, un alegre concurso de tiro celebrado sobre floridas praderas en que la sangre era el roció [no hay en el mundo muerte más bella...] (p. 5)

Como bien apunta Frédérique Langue (2014):

más allá de los usos y abusos políticos del pasado, la liturgia conmemorativa de las historias nacionales suele recordar y confortar memorias, profundizar aspectos algo olvidados de lo que se celebra, discrepar a veces y, en el mejor de los casos, propiciar esclarecedoras comparaciones y relecturas de procesos históricos afines. Tratar de un acontecimiento tan fundamental para Europa en términos de historia política, social y cultural como los dos conflictos mundiales ha sido, y sigue siendo, uno de los mayores retos historiográficos de estas últimas décadas (p. 1).

Según Campagnon, la Primera Guerra Mundial, que hasta su fin causó cerca de diez millones de muertos, otros tantos heridos:

dejó, entre sus saldos más visibles, una Europa despojada de sus atributos civilizatorios, destrozada y fragmentada. La Primera Guerra modeló todo el siglo XX. No solo liberó el germen nacionalista y militarista que llevaría a la Segunda Guerra Mundial, sino dio origen al orden geopolítico internacional posterior, marcado por la desaparición de los grandes imperios coloniales europeos, la división ideológica entre los sistemas socialista y capitalista, y el dominio globalizado de Estados Unidos (En: Hernán D. Caro, 2014: p 1).

Según especialistas como "Antoine Prost y Jay Winter, la historiografía 
sobre la Gran Guerra ha pasado por tres grandes configuraciones sucesivas. La primera, que se desarrolló entre 1918 y finales de los años cuarenta, estuvo dominada por estudios de historia militar y diplomática, empeñada en buscar los culpables. En ella, los combatientes y las sociedades fueron los grandes ausentes" (2013: s/p). Abre, entonces, la segunda etapa bajo los parámetros de la historia social de Annales, que ganó centralidad de la escena después de la derrota del nazismo. Su principal característica es enlazar ambas guerras del siglo XX. Su eje pasaba por las relaciones entre guerra y revolución. Se comenzó a "incorporar a los acontecimientos militares y diplomáticos el estudio de la opinión pública, la organización económica y a las víctimas, entre otros temas". El tercer momento, que continúa dominando de una u otra manera los estudios sobre la Gran Guerra, tiene en la cultura, entendida desde la perspectiva historiográfica del "giro cultural", su elemento central de análisis. "Este pasaje de una historia social a una historia cultural de la Gran Guerra, se hizo evidente en dos coloquios internacionales que tuvieron sede en Francia el primero en 1988 y el segundo en 1992". En cuatro años se había pasado de "sociedades europeas" a "culturas". Pero no se trató de una transición demasiado abrupta ya que partía de los estudios de las mentalidades, la opinión pública o las psicologías colectivas desarrollados en las décadas anteriores. En este sentido, la historiografía de la Gran Guerra siguió una evolución similar al conjunto de la disciplina. (Fuentes Codera, 2013: p. 14)

\section{En América Latina}

Sin embargo, en América Latina los estudios sobre la Gran Guerra podemos calificarlos, en primera instanci,a como radicalmente distintos, si bien podremos mencionar algunas contribuciones académicas en el ámbito económico especialmente, o diplomático y de espacio para la discusión del impacto de dicha confrontación en la geografía americana, lo primero que llama la atención es la escasez de estudios sesudos; a lo sumo, algo sobre las repercusiones en el continente y aún en menor --casi una nula-- reflexión sobre la formas en que los latinoamericanos participaron o influyeron en esta primera confrontación mundial.

La Primera Guerra Mundial no forma parte de la agenda investigativa actual y es un vacío que seguramente se tendrá que llenar de manera paulatina y al calor de una conciencia latinoamericana sobre los diversos

18 Desilusión y esperanzas durante la Gran Guerra: poetas y cronistas americanos

Mario Oliva-Medina 
aspectos significativos que prefiguró aquel conflicto para América Latina.

En todo caso merece mención ciertas indagaciones que están en curso, sobre todo, en el ámbito intelectual y cultural. Es sabido que la ciudad de París ejerció durante el siglo XIX hasta la Primera Guerra Mundial una atracción para todo tipo de letrados, artistitas, diplomáticos y políticos. Beatriz Colombi, afirma:

entre el 1900 y la primera guerra mundial un contingente de escritores hispanoamericanos convergió en París conformando una colonia con lazos estables: si bien existían numerosos antecedentes de viajes y exilios letrados en la centuria precedente, esta migración constituyó el primer ingreso masivo de la inteligencia hispanoamericana en un concierto internacional (2009: s/p).

De acuerdo con un reciente trabajo de Olivier Compagnon L'adieu à l'Europe. L'Amérique latine et la Grande Guerre. Argentine et Brésil, 1914-1939, ya antes del conflicto las élites latinoamericanas habían evidenciado su afán por definir y dirigir un destino colectivo pensado dentro de una radical alteridad respecto a Europa. La reconstrucción cronológica de las representaciones colectivas de ambos lados del Atlántico permite claramente reevaluar el papel del periodo 1914-1918 y de la guerra en las sociedades latinoamericanas en ese contexto de afirmación nacionalista y búsqueda de una identidad propia.

El estudio de dos naciones de migrantes, Argentina y Brasil, actores además de una economía ya internacionalizada y crisoles de una activa intelectualidad, pone de relieve el sentido de la «neutralidad activa» en el contexto de la «reforma política pacífica» del radical Hipólito Irigoyen, en el caso argentino, o de las prácticas políticas de cuño oligárquico en una república brasileña ya, sin embargo, consolidada. No en balde el ensayista brasileño Joao de Río afirmó en 1917 que «la guerra es para nosotros un despertar y un reconocimiento de nuestro propio valor» (Campagnom, 2014: 11). La prensa, los archivos diplomáticos o parlamentarios, los debates políticos y económicos evidencian, en efecto, el interés que las opiniones públicas de ambos países expresan hacia el nuevo escenario internacional fomentado por la Sociedad de naciones y la ruptura del aislacionismo norteamericano.

Pese a unas posiciones diplomáticas a veces adversas (rivalidades fronterizas y acuerdos comerciales divergentes, el llamado eje 
Washington-Río), un destino común se va forjando en los años 19141918. A finales del 1914, los intelectuales argentinos y brasileños se empiezan a movilizar valiéndose de la simbólica dicotomía, ampliamente tratada en sus respectivas literaturas, entre «civilización» (encarnada entonces por Francia) y «barbarie» (asociada a Alemania). Esta toma de conciencia a favor de los Aliados y los alistamientos de voluntarios tienen sin duda su origen en la nutrida inmigración europea, especialmente en Argentina. También habría que mencionar a las élites afrancesadas, más activas en los medios intelectuales que en otras comunidades europeas, mientras que los alemanes se relacionaban, sobre todo, con los ambientes castrenses locales (Campagnom, 2014).

La búsqueda de un «destino común» se funda además en la voluntad de participar en el «concierto de las naciones» (caso de Brasil) y de obtener provecho a la «aliadofilia» en términos de alianzas comerciales y estratégicas. Varios acontecimientos llevarían a las naciones latinoamericanas a posicionarse, desde el bloqueo aliado de 1914 hasta la declaración de guerra de Estados Unidos y el compromiso de Brasil con los Aliados (1917), incluyendo la guerra de los submarinos a partir de 1915, el establecimiento de listas negras, la Conferencia de la Paz en 1919 y la creación de la Sociedad de las Naciones. Dos principios rigen en ese aspecto el paso de una guerra europea a una guerra americana en las representaciones sociales y culturales: la solidaridad con Estados Unidos y la necesidad de preservar relaciones óptimas con las potencias europeas. (Campagnom, 2014)

\section{Poetas y cronistas americanos}

Quisiera ahora hacer un planteamiento más colindante a un conjunto de intelectuales latinoamericanos y más específicamente centroamericanos que mantuvieron una relación directa o cercana con el conflicto cuyas experiencias, dan como resultado la creación y desarrollo de una producción literaria principalmente en poesía y prosa sin par en el continente americano; ya fuera por su abundancia y diversidad, como por su calidad. Se trata de tres poetas y un cronista: Basileo Acuña (1897-1992), costarricense; Salomón de la Selva (1893-1959) y Rubén Darío (18671916), ambos nicaragüenses, y Enrique Gómez Carrillo (1873-1927), guatemalteco. Resulta altamente meritoria esta producción porque América Latina fue una zona que permaneció al margen del conflicto por largos años, hasta que abandona la

20 Desilusión y esperanzas durante la Gran Guerra: poetas y cronistas americanos Mario Oliva-Medina 
política de neutralidad en 1917, luego de la entrada de los Estados Unidos en la confrontación mundial.

Iniciemos esta aproximación con una de las figuras más notables de las letras hispanoamericanas como lo es Rubén Darío. A inicios de 1914 la inminencia de guerra era evidente en Francia. Darío siente y vive esa amenaza y procura trasladarse a Barcelona a sugerencia de sus amigos más cercanos, en mayo de 1914 comienza su viaje de regreso a su país Nicaragua. En junio inicia la guerra y envuelve a varios países de Europa hasta involucrar a gran parte del planeta. Darío no dejó de pensar, meditar y escribir sobre ese acontecimiento. Edelberto Torres Espinoza (1980), su biógrafo más importante, nos describe aquellos azarosos y finales días del poeta centroamericano: “ Yo no puedo -escribe a Piquet-continuar en Europa , pues agoté el último céntimo. Me voy a América, lleno del horror de la guerra, a decir a mucha gente que la paz es la única voluntad divina”. (1980: p. 844)

Darío sufre recaídas de su enfermedad alcohólica, de las que sale una y otra vez, pero se obsesiona con la muerte. Lee la Biblia y reza. Cae postrado en cama, delira, clama a Cristo y se pone en el pecho el crucifijo de marfil, obsequio de Amado Nervo. Sus allegados soportan y le acompañan, sobre todo en las noches, mientras lee, escribe o delira (1980: p. 846).

En su itinerario se encuentra la ciudad de Nueva York donde lo esperan algunos nicaragüenses entre ellos el joven poeta Salomón de la Selva. Se reúne con personalidades de las letras que residen en aquella ciudad, escribe crónicas e impresiones de la urbe estadounidense. Sus trabajos aparecen en periódicos hispanoamericanos como La Prensa y Las Novedades.

En 1915, se arreglan conferencias a raíz del interés de la opinión pública por la conflagración mundial. Personalidades tratan de hacer grata su estadía en Nueva York y se le entregan algunos premios como los que recibe de la Sociedad Hispánica de América. Ofrece conferencias en la Universidad de Columbia junto con uno de sus compañero de viaje, Alejandro Bermúdez, quien diserta durante una hora, mientras Darío escribe un poema titulado Pax precedido de una introducción en prosa donde explica el sentido y entorno del poema. Se percibe en esta nota si visión crítica de la sociedad materialista en la que se había convertido los Estados Unidos, que dice así:

señoras, señores: voy a dar lectura a un poema de $\mathrm{Paz}$, en medio de tantos ecos de guerra. 
Encontraréis en él un marcado carácter religioso, lo cual queda bien en este inmenso país, que a pesar de su vastas conquistas prácticas y de su constante lucha material, es el único en el mundo que tiene un 'Thanksgiving Day'. Sé que para algunas gentes, como decía el famoso M. de Buloz, director de la REVUE DES DEUX MONDES, Dios no es de actualidad. Yo creo, sin embargo, en el dios que anima a las naciones trabajadoras, y no en el que invocan los conquistadores de pueblos y destructores de vidas, Atila, Dios and Company Limited. A medida que la ciencia avanza, el gran misterio aparece más impenetrable, pero más innegable. Un Poincaré, un William James y un Bergson, son los `pioneers'del infinito. En cuanto a un ambiente de eternidad, Edgard Poe, que solamente ha escrito una o dos veces en toda su vida el nombre de Cristo, adopta una definición de Dios tomada de Granwill, quien seguramente recordó a Santo Tomás: Dios no es sino una gran Voluntad que penetra todas las cosas por la naturaleza de su intensidad. Yo creo en ese Dios. Aquí el poema que voy a tener la honra de leeros:

La oda está compuesta por 205 versos, y todo indica que la inició en
Barcelona a finales del año 1914 y culmina unos meses después en febrero de 1915 en la gran metrópolis estadounidense. El poema no es fácil de leer si consideramos la enorme cultura que posee el poeta que esta expresada en muchos de estos versos, el tema de este poema es la exaltación de paz y la condena de la guerra, estos elemento son los que le dan unidad al sentido del poema y por anclarlo en un mundo de referencia, se desliza en el clímax del poema el papel que debe jugar América Latina en esas coordenadas espacio-temporal en que están expuestos los versos:

En sangre y llanto esta la tierra antigua.

La Muerte cautelosa o abrasante, ó ambigua

pasa sobre las huellas

del Cristo de pies sonrosados

que regó lágrimas y estrellas.

La humanidad, inquieta,

ve la muerte de un papa y el nacer de un cometa

como en el año mil.

Y ve una nueva torre de Babel

desmoronarse en higuera cruel

al estampido del Cañón y del fusil.

22 Desilusión y esperanzas durante la Gran Guerra: poetas y 
Todo el poema esta bañado de su interpretación bíblica de aquel momento histórico y funciona como solución al mismo:

Y en la noche profunda de guerra, Jesucristo que el odio destierra, por el canto echó el mal de la tierra. Y se pregunta por el poder de las letras y el arte:

¿No habrá alguno de raza más joven que rompiendo a la guerra su yugo pueda unir el poder de Beethoven con el canto que da Víctor Hugo?

Fiel a su tradición más americanista cierra el poema y exalta las virtudes de una tierra de esperanza:

¡Oh pueblos nuestros! ¡Oh pueblos nuestros! Juntaos

en la esperanza y en el trabajo y la paz;

no busquéis las tinieblas, no persigáis el caos,

y no reguéis con sangre nuestra tierra feraz.
Ya lucharon bastante los antiguos abuelos

por la patria y Libertad, y un glorioso clarín

clama a través del tiempo, debajo de los cielos:

Washigton y Bolívar, Hidalgo y San Martín.

Ved el ejemplo amargo de la Europa deshecha.

Ved las trincheras fúnebres, las tierras sanguinosas,

y la Piedad y el Duelo sollozando los dos.

No; no dejéis al Odio que dispare su flecha,

llevad a los altares de la paz miel y rosas.

¡Paz a la inmensa América! ¡Paz en nombre de Dios! (Rubén Darío. Poesía 473-478)

El segundo poeta, también nicaragüense, y por azares de la vida acompañante inseparable de $\mathrm{Ru}$ bén Darío en su última estancia en Nueva York, e interlocutor en cuestiones de literatura y vida social fue Salomón de la Selva. Era un joven de apenas dieciocho años de edad; dos años más tarde, en 1917, viaja a 
Europa para enrolarse en las filas en el ejército inglés "este leones es un excelso poeta de guerra, no solo porque tocó con altura la lira durante la conflagración, sino porque también estuvo personalmente en la pelea... (Valembois, 2007: p. 198) de esa experiencia escribe un libro extraordinario y único en la historiografía literaria no solo regional sino latinoamericana, El Soldado Desconocido, publicado en 1922, bajo el sello editorial Cultura de México, cuya portada pertenece al pintor mexicano Diego Rivera.

El crítico Steven F. White, descubre un aspecto que vale la pena mencionar como es el hecho que la poesía de guerra de Salomón de la Selva en inglés, escrita entre 1916 y 1917 antes de su experiencia como combatiente, corresponde al verso compuesto por los poetas ingleses en 1914-1915 antes del horror de la ofensiva del río Somme, en julio de 1916. Esta poesía inicial con su idealismo, su elegancia refinada, su solemnidad y sus cualidades bucólicas es muy distinta de los informes desilusionados y antiheróicos desde las trincheras en obras posteriores como El Soldado Desconocido y Counter Attack, de Siegfried Sassoon. (La poesía de Nicaragua: diálogos con Francia y los Estados Unidos. Jornal de poesía. Recuperable en: http:// www.jornaldepoesia.jor.br/bh36white7.htm)

El título del poemario es una marca, una señal o indicador que nos permite relacionar la interacción con el conjunto del texto por tanto anticipa notas de referencialidad del universo imaginario. En 1921, el propio de la Selva aclara al respecto:

Ya no en John, ni Tim, ni Tommy, ni Guy el héroe de la Guerra (...) el héroe de la Guerra es el Soldado Desconocido. Es barato y a todos satisface. No hay que darle pensión. No tiene nombre. Ni familia. Ni nada, Sólo patria. (2005: p. 54-55)

Muchos de los poemas tienen títulos que pasan a ser un factor incisivo y decisivo de legibilidad del poema, vector que orienta al lector en su interpretación y sensibilidad. Observemos algunos de esos títulos: La muerte afina su violín, Mi bayoneta, Heridos, La bala, Descanso de una marcha, Comienzo de batalla, Granadas, Granadas de gas asfixiantes, Camuflaje, Carga a la bayoneta, Prisioneros, La paz. Veamos un par de ejemplos:

Mi bayoneta

¡Canto a mi bayoneta!

¡Oh fuerte, oh recta, como la memoria

24 Desilusión y esperanzas durante la Gran Guerra: poetas y cronistas americanos Mario Oliva-Medina 
que todavía guardo de mi primera novia!

Igual a como brillas,

maravillosa de sol

al presentar nosotros armas,

así brilla ella,

así me deslumbraba,

cuando pasaba sola

del convento a su casa:

Siempre vestía de blanco, nunca me miraba,

pero sé que me quería

con toda el alma...

Lo que te digo a ti se lo dije:

¡séme fiel, séme fiel!...

¿me habrá olvidado?

(Salomón de la Selva, 1922, p. 23)

Granadas de gas asfixiante

Pló-pló-pló-pló hacen las granadas,

y cuando caen, plúm.

Y en los días de sol su humo es una

nube amarillosa,

y en los días de lluvía de una

blancura esplendorosa.

¿Quién no se acuerda de los cuentos de hadas?
¿De los genios, de los duendes, de los gnomos?

¡Pló-pló-pló-pló ... plúm!

Pló-pló-pló-pló...

pló-plúm-pló!

El gas que he respirado

me dejó casi ciego,

pero olía a fruta de mi tierra,

unas veces a piña y otras veces a mango,

y hasta a guineos de los que sirven para hacer vinagre;

y aunque de sí no me hubiera hecho llorar,

Sé que hubiera llorado. (1922: p. 49-50)

El saldo de la guerra para Salomón de la Selva fue un conjunto de poemas que se referían a está en términos directos, prosaicos y en un tono de brutalidad que buscaba rimar con los hechos sórdidos que significaban las batallas, realizadas ahora con armamentos cada vez más letales. (Miguel Ángel Flores, 2005: p.18) 
Este otro más puntual sobre la actitud de su gobierno:

\section{Noticias de Nicaragua}

Pero cuando supieron

que venía a la guerra yo,

nicaragüense,

a pelear por Nicaragua,

los beatos,

y los discutidores en público,

y los hacedores de versos,

convinieron en que yo estaba loco.

(1922: p. 88)

Es probable que el poeta nunca se apartara del recuerdo de su tierra, de lo que estaba en juego en aquella contienda al final del poemario, anota en prosa poética la suerte de estas tierras y con sentimiento premonitorio, canta:

P.D. La América tropical dará al mundo los mejores poetas, los mejores pintores y los mejores santos. Como tengo que hacer de centinela no me queda tiempo para dilatarme ahora en explicaciones. Basta una: El Sol. ¡Me voy a ver la noche hasta que salga el sol! VALE. (p. 149).

El Soldado Desconocido nace de la amargura, la decepción y la desesperanza. Ungaretti, mientras a su lado caían los obuses, entonaba un canto a la vida: en medio de tanta muerte, cabía la emoción al recordar entre el humo de la pólvora. Pero en el mundo de Salomón de la Selva toda luminosidad había sido cancelada. La literatura es una enfermedad y las palabras que nos vinculan con los otros pierden su sentido (Flores, 2005: 18).

Ya me curé de la literatura

Estas cosas no hay como contarlas.

Estoy piojoso y eso es lo de menos.

De nada sirven las palabras

(1922: p. 69)

José Basileo Acuña, (1897-1992) el poeta que fue a la guerra, es una de las personalidades más influyentes en las letras de Costa Rica, sobre todo por su amplia cultura. Plasmada en su extensa obra escrita en varios campos: filosóficos, teosofía, estética, educación, psicología, historia, poeta de altos vuelos, dramaturgo, ensayista y traductor. ${ }^{1}$

1 Peggy von Mayer. Preparó en seis tomos las Obras Completas de José Basileo Acuña, publicados por la editorial Costa Rica, 2010. En las notas introductorias se reflexiona ampliamente sobre los diversos campos en que el escritor incursiona, su preocupación principal

26 Desilusión y esperanzas durante la Gran Guerra: poetas y cronistas americanos

Mario Oliva-Medina 
Con apenas 17 años viaja a Inglaterra donde inicia estudios en medicina, al estallar la Guerra en 1914 se enrola en el ejército inglés. El joven Acuña recibió la Cruz de Guerra, con siete medallas: cada una por su heroísmo. ${ }^{2}$

Según Jorge Chen Sham Acuña (2013), Acuña escribe de 1916-1919 Un episodio de instantáneas japonesas (1953) que aparece como la primera obra realizada "por el polifacético y humanista costarricense" (p.52). A simple vista, no hay relación aparente con la guerra, ni el lector comprende que se trata de un verdadero diario íntimo y poético, el cual aborda la experiencia de un soldado en el campo de batalla. "El título alude a los recursos estilísticos y la propuesta estética que significa una renovación muy temprana en el contexto centroamericano" ${ }^{3}$. El texto en mención está formado por una serie de haikai

es llenar un vacío en la historiografía literaria sobre el autor.

2 Junto a él participaron otros costarricenses como es el caso de Herbert Knorr que peleó del lado alemán, Tobías Bolaños, como aviador, y el Dr. Moreno Cañas, como cirujano, ambos lo hicieron en el frente aliado.

3 Jorge Chen Sham. Un poeta costarricense en la Primera Guerra Mundial. La Nación, Suplemento Áncora, 14 de noviembre del 2014. p. 9. Del mismo autor un análisis más profundo de esta poesía en : La Primera Guerra Mundial y la poesía centroamericana: la contienda vista por José Basileo Acuña y Salomón de la Selva. Pensamiento actual. Universidad de Costa Rica volumen 13(21), julio 2014, p. 51-67. sobre la Primera Guerra Mundial. Recoge las experiencias de diferentes batallas en las que participó Acuña. Según Von Mayer (2010), su tono, triste y conmovedor, despiertas hondas reflexiones...

En su poema Rapsodia XVIII, El siglo XX después de la Primera Guerra Mundial, se aprecia con toda la fuerza y sencillez ilocutiva del poeta lo que aquella experiencia provocaba en su alma, en su vida y en la de otros:

Y la sangre trajo sangre.

Y la derrota se convirtió en victoria.

Y la victoria fue ceniza de miseria.

Fue vinagre de desencanto en los resecos labios.

(alma mía, tú participaste en aquello.

En los campos de batalla de Francia

Quedaron sepultados tus abriles)

La juventud que peleó en aquel entonces

no tuvo mayos sino tierra yerma, las frutas de la vida las cortó en cierne,

las maduró la boca y eran amargas, 
y el corazón cántaro roto en la cisterna

y la cisterna vacía soledad en el espacio-mundo.

Heráclito se bañó en las aguas que venían de regreso. (2010: p. 427)

Pasemos a ver la figura del guatemalteco Enrique Gómez Carrillo. Crítico literario, escritor, periodista y diplomático, las crónicas de este escritor representan una de las contribuciones más grandiosas realizadas por las letras de un latinoamericano sobre el conflicto europeo de 19141918. Al considerar el conjunto de producción se observa varios centenares de páginas que aparecieron en diversos medios publicitarios, como periódicos y en formato de libros en varios países europeos. Algunas de ellas alcanzaron una diversidad de públicos al ser editadas en francés, inglés, español y ruso como lo fue el caso de Campos de batalla y campos de ruinas, con ediciones en español, francés e inglés, lo que supone un público muy diverso y heterogéneo; Crónicas de la guerra, 1915; En las trincheras 1916; Tierras mártires, 1918; La gesta de la legión, los voluntarios españoles e hispanoamericanos. Campos de batalla y campos de ruinas, 1919; y, Mata Hari, 1924. Por señalar los más sobresalientes.
Gómez Carrillo, profundamente enamorado de la cultura francesa, a la que le debía tanto, no solo sus desvaríos diplomáticos, sino también una carrera literaria y periodística, llego a convertirse en España, particularmente en el cronista principal de la guerra. Sus crónicas tomaron el lugar del teletipo frio y escueto, para transformarse en la narración más acabada no solo de lo presenciado, sino de lo trasmitido, de lo escuchado y de lo contado por aquellos que vivieron en las trincheras, los parapetos, las ciudades arrasadas, y los hospitales, el aspecto más tenebroso de uno de los mayores conflictos militares del siglo XX. (Quesada, 2014: s/p, párr. iv)

Para Gómez Carrillo, la guerra no era bella, a pesar que la escritura de este cronista se engalanaba con diversas situaciones, vivencia, historias, experiencias para que el lector tuviese una sensación del heroísmo de cada suceso, en Campos de batallas y campos de ruinas esclarece su parecer con respecto al conflicto en tono inflamado dice: por eso quiero gritar a la argentina y a la América con toda mi alma, con toda mi voz:

¡Ved lo que es la guerra ....Ved que no hay en ella armaduras lucientes, ni nobles generosidades, ni estandartes vistosos, sino sangre,

28 Desilusión y esperanzas durante la Gran Guerra: poetas y cronistas americanos

Mario Oliva-Medina 
miseria, llamas, crímenes, sollozos... ( 1916: p. 6).

El cronista de la Gran Guerra, había sido invitado en noviembre de 1915 por el mismo Ministro de Negocios Extranjeros, Théophile Delcassé, como representante de El Liberal junto con otros periodistas para visitar la geografía de la guerra, obviamente dicha misión tenía como propósito contrarrestar la propaganda alemana, meses después así lo reconoce uno de sus lectores:

los que queremos y admiramos a Gómez Carrillo deseamos que permanezca en el teatro occidente de la guerra hasta que pueda contarnos el crecimiento y multiplicación de las legiones aliadas, ocasión altísima que anhelamos para ver deshecho el imperio de la fuerza bruta vencedoras la razón y la justicia (Pérez Galdós, 1919: p. 11).

Gómez Carrillo de inmediato acepta dicha invitación y se dirige a Paris de donde sale la delegación, al menos siete veces visita los campos de batalla sobre todo el frente de guerra occidental ${ }^{4}$.

El reconocimiento de sus crónicas de guerra eran de escrutinio

4 Para mayores detalles sobre cada una de estas visitas que realiza el cronista al Frente desde 1915 a 1918, véase Enrique Gómez Carrillo. (1956). El cronista errante. Librería escolar Guatemala, pp. 308-314. internacional y muchos eruditos, escritores, artista así lo reconocían, uno de sus prologuistas ilustres; Benito Pérez Galdós (1919), se refería a ellas:

sus cuadros de guerra tienen la gracia francesa y la emoción española. Va el escritor de pueblo en pueblo, de ruina en ruina, de trinchera en trinchera, interroga a los sobrevivientes de la catástrofe; reproduce la desolación de las viviendas destruidas, el llanto mudo de los momentos despedazados por los proyectiles alemanes; recibe y nos trasmite el gemido de Marne ensangrentado, de Champagne ultrajada, de la Lorena indomable, y todo esto nos lo hace ver y sentir con la magia de su verbo sutil; es en la guerra, como en la paz, el pintor felicisímo de la Galilea, de Damasco, de las peregrinaciones a la meca, el admirable poeta de Japón, de la India, de la Clásica Grecia y del misterioso Egipto. (p. 11).

Nada escapa a la pluma de Gómez Carrillo, las trincheras, las armas, el hambre, la deserción, la amistad entre rivales, la espiritualidad, la vida y la muerte, las mujeres, los niños, los ancianos, la vida cotidiana junto a un despliegue inmenso de su saber enciclopédico, podía articular cualquier acontecimiento junto a narraciones de algún literato, pintor, 
escultura, u obra arquitectónica, la historia o la geografía.

Las cuatro figuras de las letras americanas que hemos mencionado, son parte de la influencia provocada por la confrontación bélica más traumática desarrollada hasta las primeras décadas del siglo XX, se impone el análisis de sus obras y sus vidas en este proceso, unos lo hicieron a través del verso otros por medio de la crónicas, sus contribuciones deben ser consideradas como parte del conflicto y también desde el punto de vista estrictamente literario, los caminos están abriéndose y muy probablemente con el avance de la investigación iremos descubriendo otros intelectuales pertenecientes a esa república de las letras latinoamericanas. De la que estos centroamericanos forman parte decisiva.

\section{Referencias bibliográficas}

Prost, A. y Winter, J. (2013) Penser la Grande Guerre. Un essai d'histoiriographie. En: La Gran guerra de los intelectuales. Maximiliano Fuentes Cadera (Comp.). España en Europa. Ayer 1, p. 2.

Acuña, B. (2010). Obras completas. Peggy Von Mayer (Ed.). Costa Rica: EUCR.

Caro, D. H.(2014) La gran desilusión frente a Europa. Revista Arcadia.com. Recuperable en: www.revistaarcadia.com/ impresa/periodismo/articulo/la-grandesilución-frente-a-Europa/38053

Chen-Sham, J.(2014) Un poeta costarricense en la primera guerra mundial. $\mathrm{La}$ Nación Suplemento Ancora, 14 de noviembre, p. 9.

. (2014). La Primera Guerra Mundial y la poesía centroamericana: la contienda vista por José Basileo Acuña y Salomón de la Selva. Pensamiento actual. Universidad de Costa Rica, 13(21), p. 51-67.

Colombi, B. (2009). Una ciudad letrada extraterritorial: escritores hispanoamericanos en París en el fin - de-siglo. Recuperable en: http://www.iai. spk-berlin.de/

Campagnom, O. (2014) América latina y la Gran Guerra. Argentina: Editorial Crítica.

Darío, R. Poesía. Biblioteca Ayacucho. Recuperable en: www.bibliotecayacucho.gov. ve

de la Selva, S. (1922) El Soldado Desconocido. México: Editorial Cultura.

. (2005). El Soldado Desconocido y otros poemas. Selección, introducción y bibliografía Miguel Ángel Flores. Epílogo de Pedro Henríquez Ureña .México: Fondo de Cultura Económica.

Gómez Carrillo, E. (1919). Obras completas. Madrid: Editorial Mundo Latina. 2013. Mata Hari. México: Fontamara.

30 Desilusión y esperanzas durante la Gran Guerra: poetas y cronistas americanos

Mario Oliva-Medina 
Langue, F. (2014). América Latina y la I Guerra Mundial: una historia cultural. Recuperable de: http://historia.fundacionmapfre.org/historia/es/blog/ dossier-fm/tema-i-guerra-mundial.jsp.

Junger, E. (2014). Tempestades de acero. Barcelona: TusQuest editores.

Pérez Galdós, B. (1919). Prólogo. Campos de batalla y campos de ruinas. (Enrique Gómez Carrillo). Madrid: Editorial Mundo latino.

Quesada, R. (2014). Enrique Gómez Carrillo (1873-1921) Cronista de la primera Guerra mundial. Revista Escáner Cultural, n 171, Marzo.

(2014). Imperialismo y barbarie: la primera Guerra mundial y el asesinato de Rosa Luxemburgo. Exégesis. Año 28 (75) pp. 4-19

Torres, E. (1980). La dramática vida de Rubén Darío. Costa Rica: EDUCA.

. (1956). Enrique Gómez Carrillo: el cronista errante. Guatemala: Librería Escolar.

White, S. (s/f). El Soldado Desconocido y Counter - Attack de Siegfried Sassoon. La poesía de Nicaragua: diálogos con Francia y los Estados Unidos. Jornal de poesía. Recuperable en: http://www.jornaldepoesia.jor.br/ bh36white7.htm)

Von Mayer, P. (2010). (Ed.). Obras Completas de Basileo Acuña. Costa Rica: Editorial Costa Rica. 